Check for updates

Cite this: Mater. Adv., 2021, 2, 5171

Received 31st March 2021 Accepted 17th June 2021

DOI: 10.1039/d1ma00291k

rsc.li/materials-advances

\section{Synergistic reinforcement of a reversible Diels-Alder type network with nanocellulose $\uparrow$}

\author{
Anna Peterson, ${ }^{a}$ Manta Roy, (D) a Julia Fagerlund, ${ }^{a}$ Giada Lo Re iD b and \\ Christian Müller iD *ac
}

\begin{abstract}
Covalent adaptable networks are attractive intermediates between thermosets and thermoplastics. To achieve an optimal combination of dimensional stability at the temperature of use and macroscopic flow at elevated temperatures, materials that combine two reversible networks are highly sought after. We demonstrate that such a material can be created through the addition of cellulose microfibrils to a polymer matrix that can undergo thermoreversible Diels-Alder reactions. The cellulose microfibrils and crosslinked polymer form two independent reversible networks that display clear synergistic effects on the thermomechanical properties of the nanocomposite. Above the glass transition temperature of the polymer matrix the two networks work in tandem to reduce tensile creep by a factor of 40 at $80{ }^{\circ} \mathrm{C}$, while increasing the storage modulus by a factor of 60 at the same temperature. The adaptability of the Diels-Alder network is not compromised by the addition of cellulose microfibrils, as shown by kinetic studies and repeated reprocessing. Further, the cellulose network significantly improves the dimensional stability at elevated temperatures where the Diels-Alder network dissociates.
\end{abstract}

\section{Introduction}

Covalent adaptable networks (CANs), currently receive considerable interest as next generation plastic materials. ${ }^{1-3}$ They display a previously unattainable combination of material properties that lie in between thermosets and thermoplastics, obtained via reversible crosslinking. The resulting polymer networks typically show reduced creep rates, increased stiffness and increased solvent and thermal resistance, characteristic for a thermoset. Simultaneously, the materials retain their ability for macroscopic flow, classically only displayed by thermoplastics. ${ }^{3}$ CANs can be divided into two categories based on the mechanism that underlies the reversible crosslinking chemistry: dissociative networks formed by reversible addition or condensation reactions ${ }^{4}$ and associative networks formed by reversible bond exchange processes. $^{2}$ Dissociative networks comprise crosslinks that open up at elevated temperature, leading to a complete loss of network integrity in the state of macroscopic flow. The dissociation of crosslinks allows the use of reprocessing methods such as extrusion or fused filament

\footnotetext{
${ }^{a}$ Department of Chemistry and Chemical Engineering, Chalmers University of Technology, 41296 Göteborg, Sweden. E-mail: christian.muller@chalmers.se

${ }^{b}$ Department of Industrial and Materials Science, Chalmers University of Technology, 41296 Göteborg, Sweden

${ }^{c}$ Wallenberg Wood Science Center, Chalmers University of Technology, 41296 Göteborg, Sweden

$\dagger$ Electronic supplementary information (ESI) available. See DOI: 10.1039/ d1ma00291k
}

fabrication type 3D printing, which are otherwise reserved for thermoplastic materials. ${ }^{5,6}$

One widely used thermoreversible crosslink exploits the Diels-Alder (DA) reaction between furan (F) and maleimide (MI). ${ }^{7}$ The popularity of the furan/maleimide coupling reaction stems from the relatively low temperature $\left(100-120{ }^{\circ} \mathrm{C}\right)$ of the retro Diels-Alder (rDA) decoupling reaction ${ }^{8-10}$ and the click-chemistry type nature and high chemoselectivity of the reaction. $^{7,11}$ The DA reaction is an equilibrium reaction between a forward coupling reaction, forming the adduct (A), and the reverse decoupling reaction that regenerates the reactants (eqn (1)).

$$
\mathrm{F}+\mathrm{MI} \underset{k_{\mathrm{rDA}}}{\stackrel{k_{\mathrm{DA}}}{\rightleftharpoons}} \mathrm{A}
$$

where $k_{\mathrm{DA}}$ and $k_{\mathrm{rDA}}$ are the rate constant of the DA reaction and rDA decoupling reaction, respectively.

At low temperatures (association temperature range $T_{\text {association }} \sim 50-60{ }^{\circ} \mathrm{C}$ ) the equilibrium is shifted towards the crosslinked state while at elevated temperatures (dissociation temperature range $T_{\text {diss }} \sim 100-120{ }^{\circ} \mathrm{C}$ ) the reverse reaction is dominating, leading to a loss of network integrity. ${ }^{12}$ Since 2002 , when Wudl et $a .^{8}{ }^{8}$ published their pioneering work using the DA coupling reaction to form reversibly crosslinked networks, various furan-modified molecules, ranging from oligomers ${ }^{8,9,13}$ to elastomers ${ }^{14-18}$ and other macromolecules ${ }^{5,19-21}$ have been coupled with bismaleimides or maleimide functionalized 
polymers, rendering the DA reaction the (probably) most well studied coupling reaction within CANs.

The dimensional stability and resistance to flow, even at elevated temperatures are important characteristics of thermosets. ${ }^{3}$ It is characterized by the creep of the material, i.e. the slow deformation in response to a persistent mechanical stress. The glass transition temperature $\left(T_{\mathrm{g}}\right)$ as well as the density of crosslinks in a plastic material will dictate the relaxation kinetics of the polymer chains and, hence, the creep behavior. Design of new CANs must find balance between the temperature range in which macroscopic flow is restricted, imparting dimensional stability, and the temperature range in which macroscopic flow is needed to permit reprocessability.

Apart from a sufficiently high $T_{\mathrm{g}}$ and crosslink density the introduction of dually crosslinked dynamic networks has recently been shown beneficial to arrest creep $^{22}$ e.g. by using a combination of irreversible and dynamic crosslinks ${ }^{23,24}$ or introduction of metal complexes in dynamic networks. ${ }^{25,26}$ The network forming properties of nanocellulose within a polymer matrix, however, has not been addressed in this regard. Nanocelluloses are stiff, elongated particles of cellulose with at least one dimension in the nanometer range. The numerous hydroxyl groups on the cellulose surface allow the particles to interact via hydrogen bonding. ${ }^{27}$ Composites containing a nanocellulose network are, hence, effectively dissociative networks, where hydrogen bonds between nanocellulose particles constitute the crosslinking points.

The formation of a nanocellulose network in polymer composites has been shown beneficial to arrest creep, especially in the high temperature regime. ${ }^{28}$ Composites of CANs reinforced by nanocellulose have recently been demonstrated, where the nanocellulose imparts a higher toughness, stiffness and resistance to macroscopic flow. Impregnation of a cellulose nanopaper with oligomers ${ }^{29}$ or a polymer latex ${ }^{30,31}$ of a CAN prepolymer have been shown to produce reshapable and reweldable composites. Such composites have been suggested

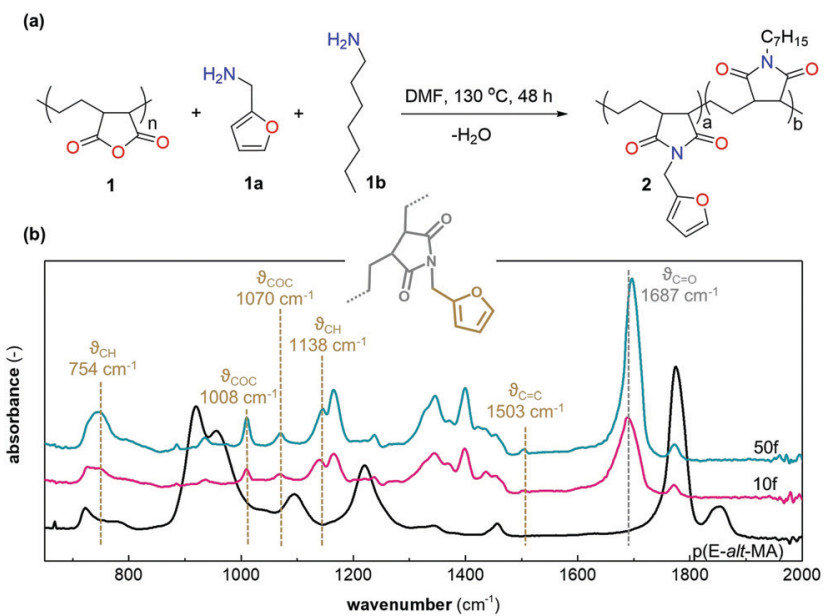

Fig. 1 (a) Modification of $p(E-a l t-M A)$ with furfuryl and heptyl amine rendering imide formation via an addition-elimination reaction, (b) FTIR absorbance spectra of $\mathrm{p}(\mathrm{E}-\mathrm{alt}-\mathrm{MA})$ and furan modified $\mathrm{p}(\mathrm{E}-\mathrm{alt}-\mathrm{MA})$. as recyclable replacements for traditional fiber reinforced thermosetting composites. ${ }^{29,32}$ Functionalized cellulose crystals have been used as crosslinkers ${ }^{33-35}$ or reinforcement ${ }^{36}$ in CAN matrices, providing an increase in the crosslinking density but a decrease in reaction rate of the reversible reaction. ${ }^{36}$ The impact of a nanocellulose reinforcing agent on the reaction rate of a dissociative CAN, however, has not yet been shown.

Here, we show a dually crosslinked dynamic network, where synergistic effects between DA reversible covalent interactions and secondary interactions between nanocellulose increase the stiffness and resistance to macroscopic flow. We synthesized a DA type dissociative CAN, which is soluble in dimethylformamide (DMF), to facilitate compounding of microfibrillated cellulose (MFC) together with the CAN. Nanocellulose materials can only be processed from polar solvents, such as water and DMF, which limits the type of CAN matrix that can be used. The commercially available copolymer poly(ethylene-alt-maleic anhydride), $\mathrm{p}$ (E-alt-MA) was modified with pendant furan groups enabled by the abundance of reactive maleic anhydride groups in the polymer chain. Apart from the ease of functionalization due to the numerous anhydrides along the polymer backbone, the synthetic product was confirmed to be soluble in DMF. The resulting polymers exhibit a $T_{\mathrm{g}}$ between $60-80{ }^{\circ} \mathrm{C}$, depending on the furan content. By varying the amount of the furan functionality, the crosslink density of the obtained DA network could be controlled. Via crosslinking with bismaleimide (BMI) we obtain fully thermoreversible DA networks. An oligomeric BMI that contains flexible alkyl segments was chosen, which plasticizes the network, as vitrification at too high temperatures would decrease the rate of the DA and rDA reactions. Below $T_{\mathrm{g}}=77{ }^{\circ} \mathrm{C}$, creep is almost completely arrested while, above $T_{\mathrm{g}}$, a higher density of crosslinks and the presence of MFC reduces creep, resulting in a combined decrease of creep by almost two orders of magnitude at $80{ }^{\circ} \mathrm{C}$. Interestingly, we find that the addition of MFC allows to drastically reduce the creep at temperatures above $T_{\text {diss }}$. While the neat CAN rapidly elongates and fractures, the addition of MFC reduces the creep strain to $20 \%$. This is attributed to the formation of a MFC network, which governs the dimensional stability of the CAN even in the dissociated state.

\section{Results and discussion}

\section{Synthesis and characterization of furan functionalized p(E-alt-MA)}

We modified the copolymer $\mathrm{p}$ (E-alt-MA) with furfuryl amine and heptyl amine through a thermally initiated additionsubstitution reaction (Fig. 1, cf. ESI $\dagger$ for detailed synthetic protocol). The ratio of furfuryl to alkyl functionality was varied, rendering two samples, 50 having $50 \mathrm{~mol} \%$ of the MA units substituted with furfuryl and 50 mol\% with heptyl, and $10 \mathrm{f}$ having $10 \mathrm{~mol} \%$ of the MA units substituted with furfuryl and $90 \mathrm{~mol} \%$ with heptyl (Table 1). The difference in furan content between the two samples later allows us to obtain CANs with different crosslinking densities. The presence of furfuryl functional groups was confirmed by ${ }^{1} \mathrm{H}$ nuclear magnetic 
Table 1 Summary of samples

\begin{tabular}{|c|c|c|c|c|}
\hline \multirow[b]{2}{*}{ Sample } & \multicolumn{2}{|c|}{$\begin{array}{l}\text { Composition of furan } \\
\text { modified } \mathrm{p}(\mathrm{E}-\text { alt }-\mathrm{MA})\end{array}$} & \multirow{2}{*}{$\begin{array}{l}\text { Furan:maleimide } \\
\text { ratio }\end{array}$} & \multirow{2}{*}{$\begin{array}{l}\text { Microfibrillatec } \\
\text { cellulose }\end{array}$} \\
\hline & $1 \mathrm{a}$ & $1 \mathrm{~b}$ & & \\
\hline $50 \mathrm{f}$ & 0.5 & 0.5 & - & - \\
\hline $10 \mathrm{f}$ & 0.1 & 0.9 & - & - \\
\hline XL50f & 0.5 & 0.5 & $2: 1$ & - \\
\hline XL10f & 0.1 & 0.9 & $2: 1$ & - \\
\hline XL50f-MFC & 0.5 & 0.5 & $2: 1$ & $10 \mathrm{wt} \%$ \\
\hline XL10f-MFC & 0.1 & 0.9 & $2: 1$ & $10 \mathrm{wt} \%$ \\
\hline
\end{tabular}

resonance spectroscopy $\left({ }^{1} \mathrm{H} \quad \mathrm{NMR}\right)$ and Fourier-transform infrared spectroscopy (FTIR). ${ }^{1} \mathrm{H}$ NMR peaks at $\delta=7.96,7.46$, 6.31 and $6.21 \mathrm{ppm}$ are ascribed to the protons of furan rings, while the peak at $\delta=4.49 \mathrm{ppm}$ is attributed to the presence of methylene protons $\left(\mathrm{CH}_{2}\right)$ of the furfuryl (Fig. S1a, ESI $\dagger$ ). A comparison between the ${ }^{1} \mathrm{H}$ NMR spectra of $50 \mathrm{f}$ and $10 \mathrm{f}$ (Fig. S1, ESI $\dagger$ ) shows the drastically higher content of alkyl protons for 10f, attributed to the higher grafting density of heptyl instead of furfuryl. The $\mathrm{CH}_{3}$ proton from the heptyl chain is observed at $\delta=0.83 \mathrm{ppm}$, where the integral value of $10 \mathrm{f}$ is about 8 times as high compared to 50f. A quantitative assignment of the relative grafting densities from ${ }^{1} \mathrm{H}$ NMR, however, is not possible due to overlap of the alkyl proton peaks.

FTIR spectroscopy was used to further confirm grafting of furan groups and imide formation (Fig. 1b), as well as quantification of the furan graft density. Characteristic peaks are the furan ring asymmetric and symmetric vibration of COC $\left(\vartheta_{\mathrm{COC}}=\right.$ $1070 \mathrm{~cm}^{-1}$ and $1008 \mathrm{~cm}^{-1}$ ), the $\mathrm{CH}$ in-plane deformation $\left(\vartheta_{\mathrm{CH}}=1138 \mathrm{~cm}^{-1}\right)$, the $\mathrm{C}=\mathrm{C}$ double bond stretching vibration $\left(\vartheta_{\mathrm{C}=\mathrm{C}}=1503 \mathrm{~cm}^{-1}\right)$ and the significant $\mathrm{CH}$ out of plane deformation $\left(\vartheta_{\mathrm{CH}}=754 \mathrm{~cm}^{-1}\right)$. Moreover, the disappearance of the anhydride peaks $\left(\vartheta_{\mathrm{C}=\mathrm{O}}=1856 \mathrm{~cm}^{-1}\right.$ and $\left.1776 \mathrm{~cm}^{-1}\right)$ and the simultaneous appearance of imide peaks $\left(\vartheta_{\mathrm{C}=\mathrm{O}}=1687\right.$ $\mathrm{cm}^{-1}$ and $1773 \mathrm{~cm}^{-1}$ ) confirms grafting of $\mathrm{p}(\mathrm{E}-$ alt-MA) with alkyl and furfuryl. The maleic anhydride groups are prone to moisture absorption and thereby hydrolyze into dicarboxylic acid, a conversion that reduces the reactivity of the carbonyl group and hence the efficiency of nucleophilic substitution. However, the acid peak $\left(\vartheta_{\mathrm{C}=\mathrm{O}}=1710 \mathrm{~cm}^{-1}\right)$ cannot be spotted in pristine $\mathrm{p}(\mathrm{E}-$ alt-MA) while the presence of anhydride characteristic peaks $\left(\vartheta_{\mathrm{C}=\mathrm{O}}=1856 \mathrm{~cm}^{-1} \text { and } 1776 \mathrm{~cm}^{-1}\right)^{37}$ is evident (Fig. 1b). Quantification of the degree of furan substitution was done based on the area of the furan peak, centered around $\vartheta_{\mathrm{CH}}=754 \mathrm{~cm}^{-1}$ (Table 2, applied equations and raw data are

Table 2 Furan graft density, thermo-physical data and molecular weight distribution of functionalized and non-functionalized $p(E-a l t-M A)$

\begin{tabular}{lllllll}
\hline Sample & $\begin{array}{l}\text { Furan graft } \\
\text { density }^{a}(\%)\end{array}$ & $\begin{array}{l}T_{\mathrm{g}}{ }^{b} \\
\left({ }^{\circ} \mathrm{C}\right)\end{array}$ & $\begin{array}{l}T_{\mathrm{d}}(5 \%)^{c} \\
\left({ }^{\circ} \mathrm{C}\right)\end{array}$ & $\begin{array}{l}M_{\mathrm{n}}{ }^{d} \\
\left(\mathrm{~kg} \mathrm{~mol}^{-1}\right)\end{array}$ & $\begin{array}{l}M_{\mathrm{w}}{ }^{d} \\
\left(\mathrm{~kg} \mathrm{~mol}^{-1}\right)\end{array}$ & $\mathrm{PDI}^{d}$ \\
\hline $\mathrm{p}(\mathrm{E}-$ alt-MA) & & 149 & $>300$ & 39 & 139 & 3.6 \\
10f & 12 & 60 & $>300$ & 97 & 395 & 4.1 \\
50f & 55 & 77 & $>300$ & 73 & 417 & 5.7
\end{tabular}

Deduced from. ${ }^{a}$ FTIR. ${ }^{b}$ DSC. ${ }^{c}$ TGA. ${ }^{d}$ GPC. found in Fig. S2, ESI $\dagger$ ). Further, elemental analysis was used to confirm grafting of furfuryl and heptyl to the p(E-alt-MA) backbone. ${ }^{38}$ The experimental results are in excellent agreement with the predicted mass fraction of the repeating units in case of both 50f and 10f, where especially the amount of nitrogen, stemming from imide formation between anhydride and amine confirms a high yield of the grafting reaction (Table S1, ESI $\dagger$ ).

The number-average molar mass $\left(M_{\mathrm{n}}\right)$, from gel permeation chromatography (GPC) analysis, is increased from $40 \mathrm{~kg} \mathrm{~mol}^{-1}$ for neat $\mathrm{p}\left(\mathrm{E}-\right.$-alt-MA) to 70 and $100 \mathrm{~kg} \mathrm{~mol}{ }^{-1}$ for $50 \mathrm{f}$ and $10 \mathrm{f}$, respectively (Table 2 and Fig. S3, ESI $\dagger$ ). The increase in molar mass of the repeat unit obtained after functionalization is expected to be about $70 \%$, with a slightly higher mass for the 10 repeat unit due to the abundance of heptyl chains. GPC analysis hence confirms successful functionalization of $\mathrm{p}$ (E-alt-MA). The discrepancy between expected mass increase and the experimental results is ascribed to differences in the hydrodynamic radii of the polymers compared to the polystyrene standard used, while also bearing in mind that the samples show a high polydispersity (PDI).

\section{CAN preparation via Diels-Alder crosslinking}

We crosslinked the functionalized p(E-alt-MA) polymers (10f and 50f) with oligomeric bismaleimide (oligo-BMI) using a solvent casting procedure ( $c f$. Experimental) to form dissociative CANs, denoted XL10f and XL50f (Fig. 2a and Table 1). A molar stoichiometry of $F / M=2: 1$ was chosen due to the incomplete conversion of the equilibrium controlled DA reaction for a stoichiometric ratio $(F / M=1) \cdot{ }^{39}$ The DA reaction between furan modified $\mathrm{p}$ (E-alt-MA) and oligo-BMI renders a thermally reversible polymer network. The reversible nature was confirmed by solubility tests where the initial reaction mixture,

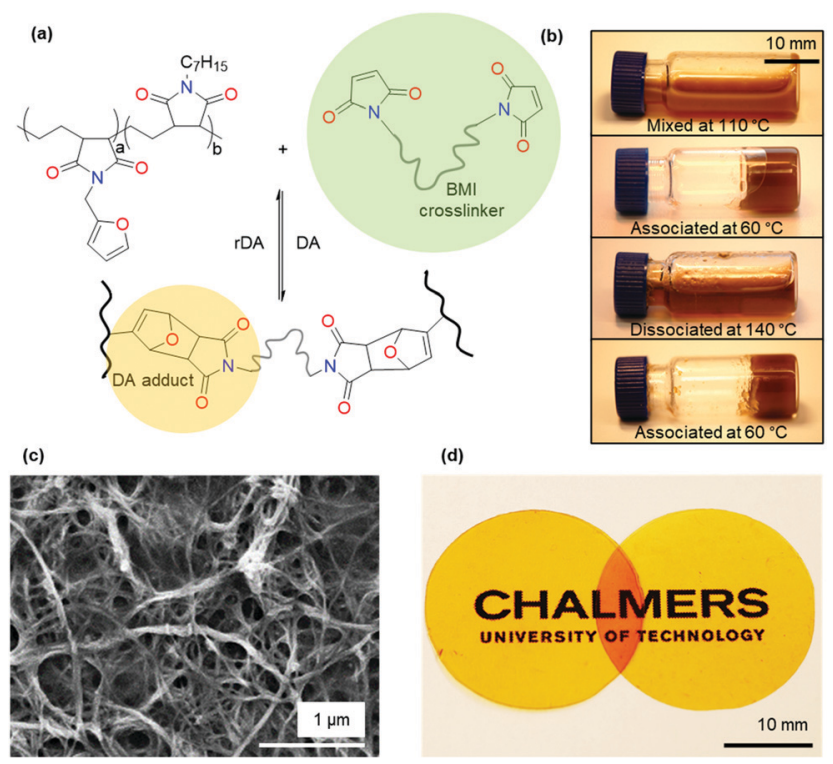

Fig. 2 (a) Synthesis of the Diels-Alder type dissociative CAN via bismaleimide crosslinking, (b) the reversible sol-gel transition process of the XL50f sample in DMF, (c) SEM micrograph of MFC, (d) photograph of XL5Of (left) and XL50f-MFC (right) showcasing the efficient dispersion of MFC in the XL50f matrix. 
containing 50f and oligo-BMI dissolved in DMF, formed a gel after thermal treatment at $60{ }^{\circ} \mathrm{C}$ overnight (Fig. 2b). Upon heating the mixture at $140{ }^{\circ} \mathrm{C}$, the gel reverts back to the liquid state, a clear light brown liquid, which again may be turned into a gel by annealing at $60{ }^{\circ} \mathrm{C}$.

As described above, the design of the here presented CAN allows for dissolution in DMF (Table S2 (ESI $\dagger$ ), solubility chart). Network formation of nanocellulose in composites processed from DMF has been previously reported, ${ }^{40,41}$ making our CAN ideal for the study of formation of a second network, based on MFC (Fig. 2c). Samples containing $10 \mathrm{wt} \%$ MFC were prepared with the same solvent casting procedure as was used for the neat CANs. Once dried, all samples were cured at $60{ }^{\circ} \mathrm{C}$ for at least $60 \mathrm{~h}$ to ensure complete crosslinking. The progress of crosslinking was followed by FTIR spectroscopy, specifically the intensity of the absorption peak of the out of plane bending of the olefinic protons of maleimide $\left(\vartheta_{\mathrm{CH}}=828 \mathrm{~cm}^{-1}\right),{ }^{42}$ which reaches a stable value after about $20 \mathrm{~h}$ at $60{ }^{\circ} \mathrm{C}$ (Fig. S4, ESI $\dagger$ ). The visual appearance of cured films is equivalent for samples with and without MFC. Films are bright orange, homogenous and transparent (Fig. 2d). The lack of visible aggregates indicates efficient dispersion of MFC in the CAN.

DSC heating thermograms of pristine $\mathrm{p}(\mathrm{E}-$ alt-MA) reveal a high $T_{\mathrm{g}}$, around $145^{\circ} \mathrm{C}$. After introduction of furan groups and alkyl chains the $T_{\mathrm{g}}$ is significantly reduced. DSC thermograms of $10 \mathrm{f}$ and $50 \mathrm{f}$ display a $T_{\mathrm{g}}$ of 60 and $77^{\circ} \mathrm{C}$, respectively (Fig. S5a (ESI $\dagger$ ) and Table 1). The decrease in $T_{\mathrm{g}}$ is attributed to the presence of flexible alkyl chains and bulky furan groups, increasing the mobility of the polymer. The oligomeric BMI crosslinker ( $c f$. Fig. S5b (ESI $\dagger$ ) for molecular structure) used for CAN formation can be viewed as a simultaneous crosslinker and plasticizer, due to the long flexible alkyl segments. Post crosslinking, the magnitude of the heat flow step, which indicates the $T_{\mathrm{g}}$, has decreased while new transitions arise from the thermal history of the crosslinked samples (Fig. S5c, ESI $\dagger$ ). While the DSC heating thermograms of XL10f and XL50f do not allow for an unambiguous assignment of the $T_{\mathrm{g}}$ of the CANs, they indicate that the $T_{\mathrm{g}}$ did not significantly increase, in agreement with dynamic mechanical analysis (DMA) thermograms (Fig. S6, ESI $\dagger$ ). Additionally, we observe two broad endothermic peaks in the DSC heating thermograms of XL50f and XL50f-MFC, which are attributed to the rDA reaction of the two DA adduct stereoisomers. The endothermic peaks centered around $170{ }^{\circ} \mathrm{C}$ and $145{ }^{\circ} \mathrm{C}$ (Fig. S5c, ESI $\dagger$ ) are ascribed to the rDA reaction of the more thermally stable exo adduct and the less stable endo adduct, respectively. ${ }^{43}$ The peak temperatures of the rDA endotherms are at the higher end of the range of temperatures reported for DA systems, for which the equilibrium is typically shifted towards the dissociated state at temperatures above $120{ }^{\circ}$ C. $^{7}$ DSC thermograms feature very broad transitions with an onset at about $120{ }^{\circ} \mathrm{C}$ (Fig. S5c, ESI $\dagger$ ), which also correlates with the softening point observed in DMA thermograms ( $c f$. discussion below). We ascribe the broad endotherms and relatively high peak temperatures of the rDA endotherms to slow relaxation kinetics of the network, as the network points are attached to macromolecular chains. ${ }^{5,44}$ The endotherms of the
rDA reaction for XL10f are less pronounced due to the lower crosslinking density.

\section{Kinetics of the DA and rDA reaction}

We studied the impact of the furan content and the addition of nanocellulose on the kinetics of the DA association. The kinetics of the DA and rDA reactions depend on the local mobility of the molecules involved in the reaction, while the overall processability depends on the macroscopic viscosity of the material. While the local mobility and viscosity are similar in some systems, such as oligomer mixtures and many neat polymers, in case of e.g. composites, a material may show a high resistance to melt flow, but still feature a high local reactivity. Decoupling of the local mobility and viscosity was demonstrated for associative CANs reinforced with cellulose nanomaterials, which display reversible crosslink chemistry and at the same time a higher stiffness and resistance to flow. ${ }^{34,36,45}$ However, the impact of a nanocellulose reinforcing agent on a dissociative CAN is yet to be shown. We used FTIR spectroscopy, and specifically, the maleimide absorption peak $\left(\vartheta_{\mathrm{CH}}=828 \mathrm{~cm}^{-1}\right)$ to follow the course of the reaction at different temperatures (Fig. 3a). The relative conversion, $R_{\mathrm{IR}}$, was calculated using the peak intensities (MI) according to eqn (2) where the C-H methyl peak $\left(\vartheta_{\mathrm{CH}}=722 \mathrm{~cm}^{-1}\right)$ was used for normalization.

$$
\begin{aligned}
& R_{\mathrm{IR}}=1-\frac{\left.\frac{\mathrm{MI}_{828}}{\mathrm{MI}_{722}}\right|_{t}}{\left.\frac{\mathrm{MI}_{828}}{\mathrm{MI}_{722}}\right|_{t=0}} \\
& \frac{\mathrm{d} X}{\mathrm{~d} t}=k_{\mathrm{DA}}(1-X)^{n} \\
& k_{\mathrm{DA}} t=-\ln (1-X) \\
& \ln k=\frac{-E_{\mathrm{a}}}{R T}+\ln A
\end{aligned}
$$

$R_{\mathrm{IR}}$ for each sample was calculated from 60 minute isotherms at 60, 70, 80 and $90{ }^{\circ} \mathrm{C}$ (Fig. S7a, ESI $\dagger$ ). We here assume, in line with earlier reports, ${ }^{18,46,47}$ that the initial stage of the reaction is dominated by the forward reaction at lower temperatures and by the reverse reaction at higher temperatures. A simplified $n$-level reaction model (eqn (3)) is hence used to describe the kinetics of the forward DA reaction, ${ }^{18,46,48}$ where a pseudo first order reaction, $n=1$, gives the best fit ( $c f$. Fig. S7b and Table S3 (ESI $\dagger$ ) for comparison between pseudo first and second order reaction kinetics). The validity of using pseudo first order conditions in the kinetic analysis is further endorsed by the reactant stoichiometry, $F / M=2: 1$.

The initial slope of $R_{\mathrm{IR}}(t)$ was fitted with eqn (4) to determine the apparent rate of the DA association reaction, $k_{\mathrm{DA}}$. The slope is increasing with the isothermal annealing temperature (Fig. S7a, ESI $\dagger$ ). The growing impact of the reverse reaction at high temperatures and long reaction times is indicated by the fact that the consumption of maleimide after $60 \mathrm{~min}$ is higher at 70 and $80{ }^{\circ} \mathrm{C}$ compared to $90{ }^{\circ} \mathrm{C}$ even though the initial 

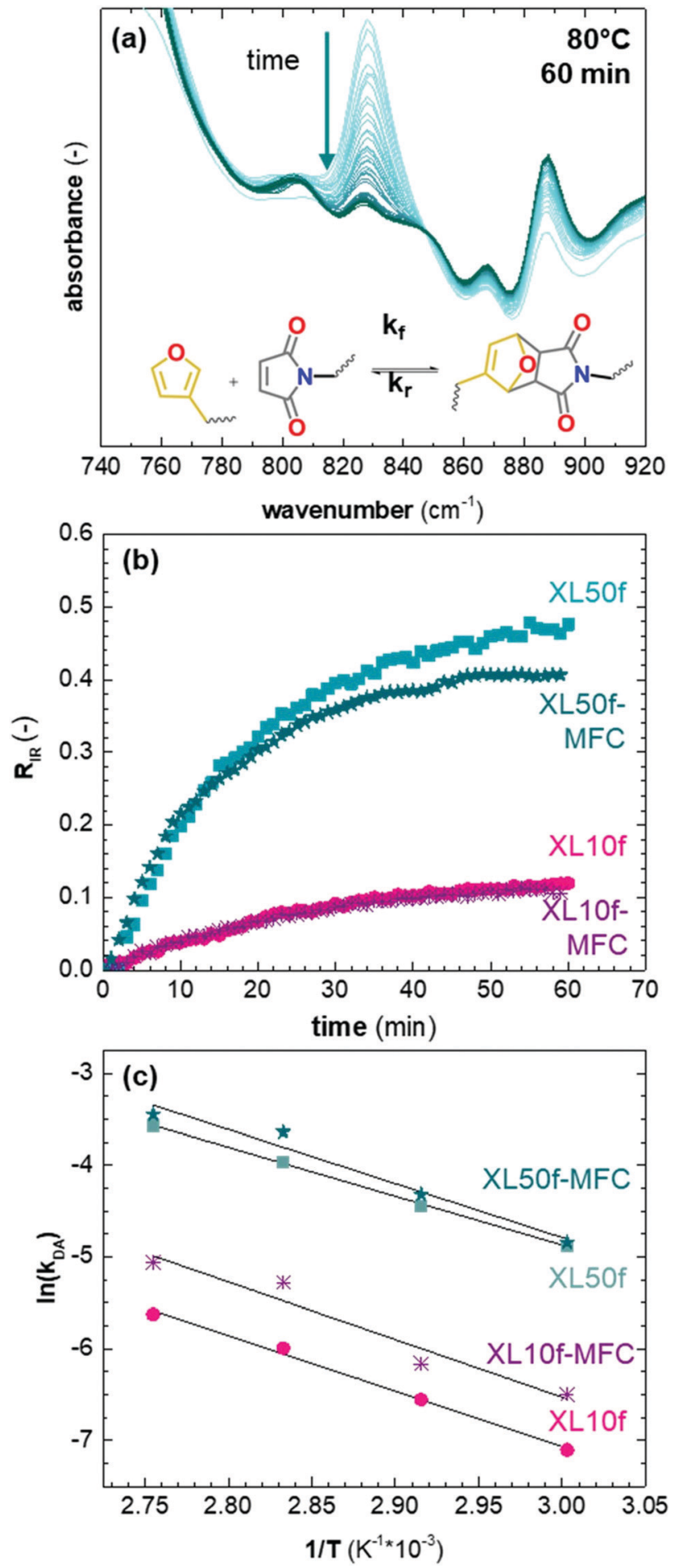

Fig. 3 (a) FTIR spectra showing the reduction of the maleimide peak at $828 \mathrm{~cm}^{-1}$ during a $60 \mathrm{~min}$ isotherm at $80^{\circ} \mathrm{C}$, (b) the relative conversion, $R_{\mathrm{IR}}$, deduced for $\mathrm{XL10f}$ and $\mathrm{XL50f}$ with and without MFC at $80{ }^{\circ} \mathrm{C}$, and (c) Arrhenius plots of $\ln \left(k_{\mathrm{DA}}\right)$ versus reciprocal temperature.

consumption of maleimide at $90{ }^{\circ} \mathrm{C}$ is faster. $R_{\mathrm{IR}}$ was also compared for XL10f and XL50f where the maleimide consumption pattern is similar for the samples with and without MFC (Fig. 3b), giving a first indication that the addition of nanocellulose does not drastically affect the kinetics of the association reaction. Next, the rate coefficients were fitted using the linearized version of the Arrhenius equation (eqn (5)) to determine the pre-exponential factor $(A)$ and activation energy $\left(E_{\mathrm{a}}\right)$ for the reaction (Fig. 3c). Activation energies of $E_{\mathrm{a}}=49.0$ and $44.3 \mathrm{~kJ} \mathrm{~mol}^{-1}$ were obtained for XL50f with and without MFC, respectively, whereas XL10f featured a slightly higher $E_{\mathrm{a}}$ of 52.2 and $50.3 \mathrm{~kJ} \mathrm{~mol}^{-1}$ (Table 3). The values obtained are within the range of $E_{\mathrm{a}}$ reported for DA association in polymer melts, which are typically $30-60 \mathrm{~kJ} \mathrm{~mol}^{-1} \cdot{ }^{47-49}$ The small difference in activation energy between samples with and without MFC suggests that the local mobility and macroscopic viscosity are indeed decoupled, giving rise to CAN type materials which display resistance to macroscopic flow without drastically affecting the reaction kinetics.

\section{Crosslinking density}

Besides the $T_{\mathrm{g}}$ and the presence of a stiff reinforcement, the crosslinking density has been identified as a key factor affecting the creep resistance of materials. The molecular weight between crosslinks, $M_{\mathrm{c}}$, of our samples was calculated according to

$$
M_{\mathrm{c}}=\left(\frac{2}{M_{\mathrm{n}}}+\frac{\sigma}{\rho R T\left(\lambda_{\mathrm{hot}}-\lambda_{\mathrm{hot}^{-2}}\right)}\right)^{-1}
$$

where $M_{\mathrm{n}}$ is the number average molecular weight, $\sigma$ is the applied stress, $\rho$ is the density of the sample at $80{ }^{\circ} \mathrm{C},(c f$. Experimental and Table S4, ESI $\dagger$ ), $R$ is the universal gas constant, $\lambda_{\text {hot }}=L_{\text {hot }} / L_{0}$ is the creep extension relative to the initial length $\left(L_{0}\right)$ at the creep temperature, $T=80{ }^{\circ} \mathrm{C}$. Eqn (6) is derived from classic rubber elasticity theory with the assumption that the positions of the network points are approximately affine in the macroscopic strain. ${ }^{50,51}$ The creep temperature was chosen as $80{ }^{\circ} \mathrm{C}$, i.e. above $T_{\mathrm{g}}$ but below $T_{\text {diss }} . M_{\mathrm{c}}$ from creep experiments (Fig. S8, ESI $\dagger$ ) are compared to a theoretical estimation of $M_{\mathrm{c}}$ assuming that all available maleimide groups are consumed (Table 4). The discrepancy between theoretical values and those obtained from creep data is likely due to a non-complete consumption of imides, which is also indicated by FTIR as the maleimide signature at 828 $\mathrm{cm}^{-1}$ is not completely vanished even after $60 \mathrm{~h}$ crosslinking at $60{ }^{\circ} \mathrm{C}$ (Fig. S4a, ESI $\dagger$ ). The experimental $M_{\mathrm{c}}$ of XL50f is $8 \mathrm{~kg} \mathrm{~mol}^{-1}$ whereas $M_{\mathrm{c}}$ of XL10f is more than twice as high, $20 \mathrm{~kg} \mathrm{~mol}^{-1}$. For reference, typical values of $M_{\mathrm{c}}$ for crosslinked elastomers are in the range of $5-20 \mathrm{~kg} \mathrm{~mol}^{-151}$ and for crosslinked polyethylene around $6 \mathrm{~kg} \mathrm{~mol}{ }^{-1}{ }^{52}$

\section{Thermo-mechanical characterization}

DMA thermograms show the synergistic effect between formation of a DA type CAN and reinforcement with MFC (Fig. 4).

Table 3 Activation energy $\left(E_{\mathrm{a}}\right)$ and pre-exponential factor $(A)$ for the association reaction calculated from pseudo first order kinetics using the Arrhenius equation

\begin{tabular}{llll}
\hline Sample & $E_{\mathrm{a}}\left(\mathrm{kJ} \mathrm{mol}^{-1}\right)$ & $A\left(\mathrm{~s}^{-1}\right)$ & $R^{2}$ \\
\hline XL50f & 44.3 & 11.1 & 0.999 \\
XL50f-MFC & 49.0 & 12.9 & 0.967 \\
XL10f & 50.3 & 11.1 & 0.995 \\
XL10f-MFC & 52.2 & 12.32 & 0.946
\end{tabular}


Table $4 \quad M_{c}$ and $E^{\prime}$ of the DA type CANs

\begin{tabular}{llllll}
\hline & \multicolumn{2}{l}{$M_{\mathrm{c}}\left(\mathrm{kg} \mathrm{mol}^{-1}\right)$} & & $E^{\prime}$ at $80{ }^{\circ} \mathrm{C}(\mathrm{MPa})$ \\
\cline { 2 - 3 } Sample & $\begin{array}{l}\text { Theoretical } \\
\text { minimum }\end{array}$ & Experimental & Associated & Dissociated \\
\hline XL50f & 5 & 8 & 74 & 4.4 \\
XL10f & 11 & 20 & 49 & 0.13 \\
p(E-alt-MA) & - & - & - & 1560
\end{tabular}

The impact of CAN formation on the storage modulus, $E^{\prime}$, below $T_{\text {diss }}$ is evident in case of XL50f, which was either cured $\left(60{ }^{\circ} \mathrm{C}\right.$, $60 \mathrm{~h})$ or dissociated $\left(160{ }^{\circ} \mathrm{C}, 15 \mathrm{~min}\right.$ with subsequent quick cooling to RT) prior to the DMA experiment. DA crosslinking in XL50f increases $E^{\prime}$ by a factor 2 at $40{ }^{\circ} \mathrm{C}$ (below $T_{\mathrm{g}}$ ) and almost a factor 20 at $80{ }^{\circ} \mathrm{C}$ (above $T_{\mathrm{g}}$ ) compared to the dissociated sample. Similar results are seen for XL10f, although with a smaller effect from CAN formation due to the lower crosslink density (Fig. S6, ESI $\dagger$ ). The addition of MFC to XL50f further increases $E^{\prime}$ by a factor 2 at $40{ }^{\circ} \mathrm{C}$, a factor 30 at $80{ }^{\circ} \mathrm{C}$ and at least 2 orders of magnitude at $160{ }^{\circ} \mathrm{C}$ (above $T_{\text {diss }}$ ). The combined effect of formation of the DA type CAN and MFC addition is a factor 4 at $40{ }^{\circ} \mathrm{C}$ and a factor 60 at $80{ }^{\circ} \mathrm{C}$. The increase in $E^{\prime}$ is directly related to the dimensional stability and resistance to flow in these CAN composites.

The set of CANs synthesized in this study allowed us to examine the creep compliance as a function of three different parameters: the crosslink density, the $T_{\mathrm{g}}$ and the presence of a second network of MFC. The impact of crosslink density was probed by creep experiments of XL50f and XL10f at $80{ }^{\circ} \mathrm{C}$, above the $T_{\mathrm{g}}$ of CANs. We find that the crosslink density has a significant impact on the creep compliance, where XL10f and XL50f show creep strains of 20 and 5\%, respectively (Fig. 5a). XL10f also shows a much larger instantaneous strain upon subjecting the sample to the applied stress, which correlates

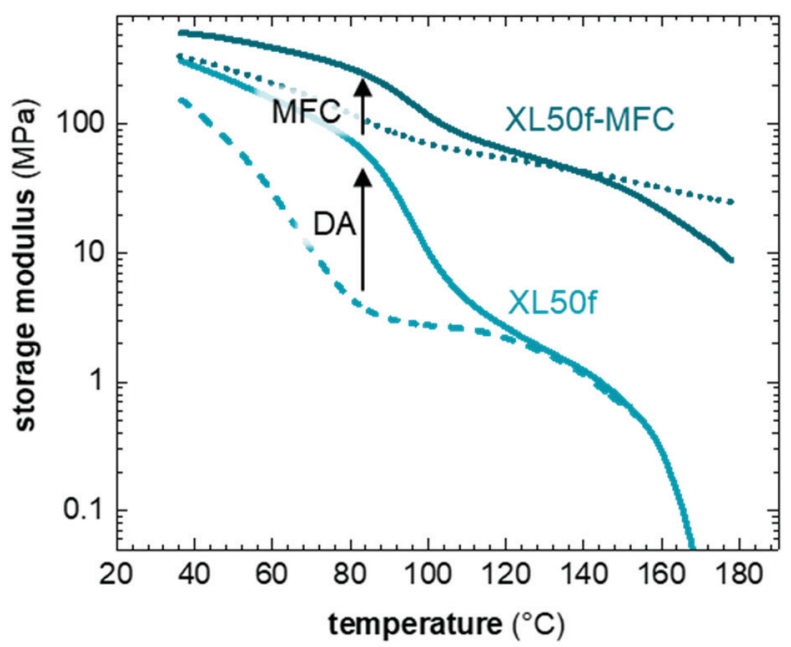

Fig. 4 DMA thermograms of XL50f with and without MFC. Dashed and dotted lines are samples of XL50f and XL50f-MFC, respectively, that, prior to analysis, were dissociated at $160{ }^{\circ} \mathrm{C}$ and rapidly cooled to prevent crosslink formation. with the lower crosslink density, as the long polymer segments between crosslinks can uncoil and align in the direction of stress, a behavior which is suppressed by the higher crosslink density in XL50f. The XL50f sample was additionally probed at $40{ }^{\circ} \mathrm{C}$, e.g. below $T_{\mathrm{g}}$ (Fig. 5b), by which the creep strain is reduced, from $5 \%$ to around $1 \%$ after $180 \mathrm{~min}$ of creep at $\sigma=$ $50 \mathrm{kPa}$. A similar reduction of creep strain is seen upon addition of MFC to the XL50f sample (Fig. 5c), again showing the synergistic effect of the CAN and MFC on the thermomechanical properties. To probe the effect of MFC only, we carried out creep tests at $140{ }^{\circ} \mathrm{C}$, above $T_{\text {diss }}$. At this temperature the DA equilibrium is heavily shifted towards the reactant side and XL50f consequently rapidly elongates and ultimately fractures after reaching a creep strain of more than $200 \%$, whereas the addition of nanocellulose arrests creep and results in a creep strain of not more than $4 \%$ after 180 min of creep (Fig. 5d).

Seemingly, MFC arrests the flow of the macromolecular chains in the dissociated state. MFC is a known rheology modifier, increasing the viscosity of melts and suspensions. ${ }^{53}$ However, this effect alone is not sufficient to explain the complete arrestment of creep. Earlier publications have shown a strong reinforcing effect of nanocellulose networks in low modulus polymers ${ }^{54-56}$ and network formation has also been shown to effectively arrest creep at high tempeature. ${ }^{28}$ Numerous hydrogen bonds, as well as entanglements between the individual cellulose fibrils allow formation of a reinforcing network that can transmit mechanical stress, taking load from the dissociated DA network. The MFC fraction at which a continuous network of nanocellulose is predicted to form, i.e. the percolation threshold, is in the range of $3 \mathrm{wt} \%$, based on the aspect ratio of the fibrils ( $c f$. ESI $\dagger$ for calculation of the percolation threshold). The considerably higher MFC content of $10 \mathrm{wt} \%$ in our CAN based composites, in combination with solution casting of composites using DMF, is likely to give rise to the formation of a nanocellulose network. A second sample of XL50f reinforced with a lower amount of MFC, $5 \mathrm{wt} \%$, showed a similar creep resistance as the sample containing $10 \mathrm{wt} \%$ MFC, where creep is almost completely arrested even at $140{ }^{\circ} \mathrm{C}$ and the final creep strain after $180 \mathrm{~min}$ is in the range of a few percent (Fig. S9, ESI $\dagger$ ). MFC, hence, forms a network even at concentrations close to the theoretical percolation threshold, which indicates efficient dispersion of MFC in the matrix.

Further, the visual appearance of films, where aggregates cannot be spotted, as well as DMA temperature ramps where the rubbery plateau extends into the high temperature region both indicate that a MFC network has indeed formed. The presence of such a network strongly enhances the resistance to creep, especially of the dissociated CAN samples.

\section{Thermal cycling}

We examined repeated association and dissociation of the DA adduct of XL50f with and without MFC during 5 temperature cycles. We gathered spectroscopic information, following the intensity of the maleimide FTIR peak $\left(\vartheta_{\mathrm{CH}}=828 \mathrm{~cm}^{-1}\right)$, and recorded the magnitude of $E^{\prime}$ with DMA as a function of 

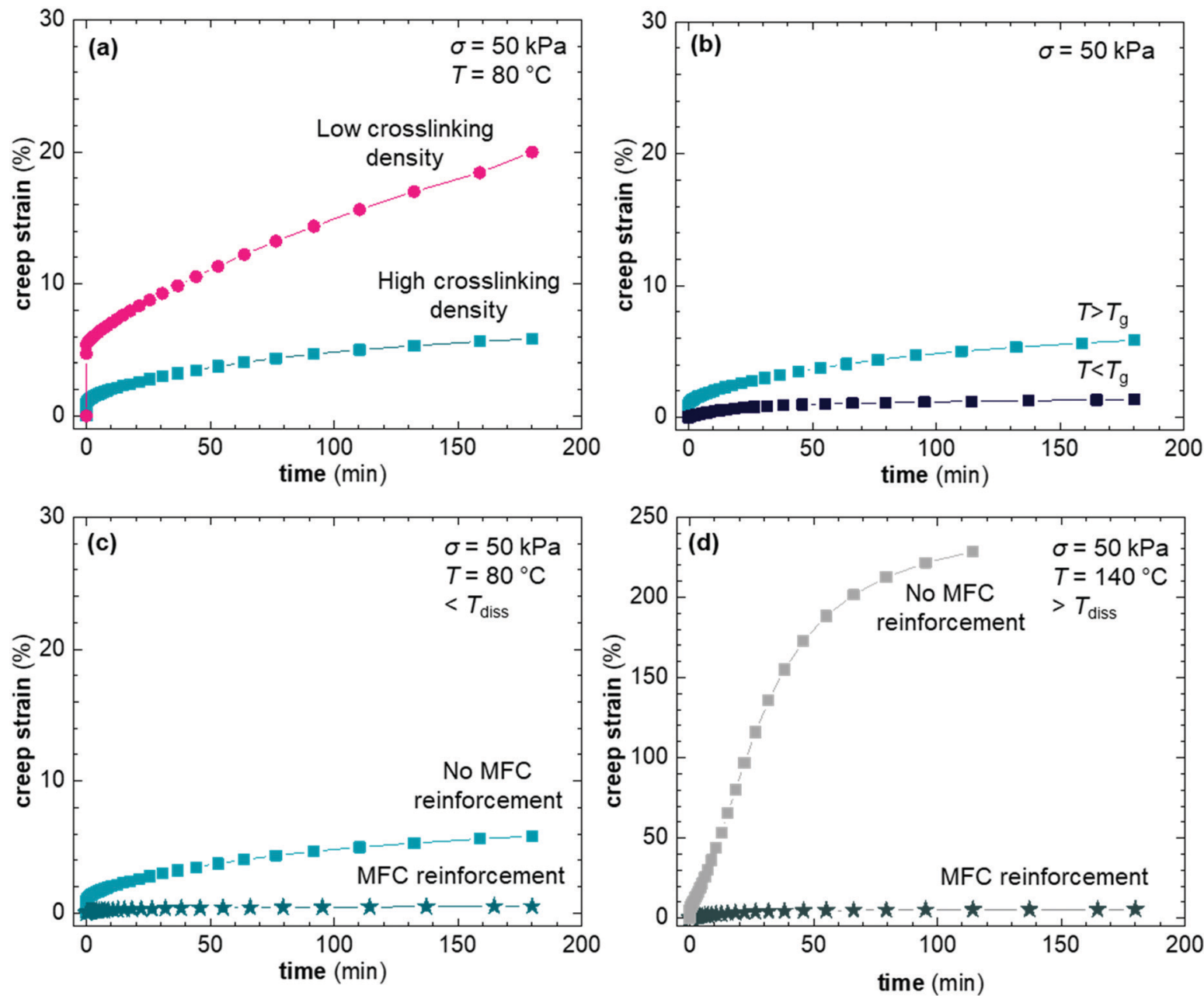

Fig. 5 Creep strain as function of time for (a) XL10f and XL50f having different degree of crosslinking, (b) XL50f at temperatures above and below $T_{\mathrm{g}}$, i.e. 80 and $40{ }^{\circ} \mathrm{C}$, (c) XL50f with and without cellulose addition in the associated state and (d) XL50f with and without cellulose addition in the dissociated state.

temperature (Fig. 6). During each cycle the samples were associated at $60{ }^{\circ} \mathrm{C}$ for $240 \mathrm{~min}$ and then dissociated for $15 \mathrm{~min}$ at $140{ }^{\circ} \mathrm{C}$.

We observe a strong response to the repeated temperature cycling. The normalized maleimide peak intensity for XL50f varies between 1 and 0.7 while $E^{\prime}$ varies between 1-100 MPa and 20-300 MPa for XL50f and XL50f-MFC, respectively (Fig. 6b). It should be noted that the DMA data show a progressive slight increase in the modulus of the dissociated state for both samples. During every cycle $E^{\prime}$ of dissociated XL50f increases with, on average, 5\% while dissociated XL50f-MFC displays an average increase of $3 \%$. We argue that a fraction of the crosslinks either do not have time to dissociate during the $140{ }^{\circ} \mathrm{C}$ isotherm or that a small fraction of permanent crosslinks is formed during temperature cycling. The spectroscopic analysis (Fig. 6a), however, suggests that the time and temperature for dissociation is sufficient, and that possible covalent bonds that may form do not involve the maleimide group. One plausible side reaction could be attributed to moisture absorption of the anhydrides during synthesis, resulting in the formation of carboxylic acids. These acids could form permanent crosslinks by reaction with secondary amides, resulting from ring opening of the imide. A small trace of secondary amides is visible in the ${ }^{1}$ HNMR spectra of 50f, while the same peak is not seen in $\mathrm{p}(\mathrm{E}-$ alt-MA) and $10 \mathrm{f}$ (Fig. S10, ESI $\dagger$ ). Aromatization of the DA adducts via dehydration is another possible side-reaction, which would yield permanents crosslinks. Aromatization in the bulk has been reported after curing DA adducts at temperatures above $180{ }^{\circ} \mathrm{C}$ for several hours. ${ }^{7,57}$ We argue that aromatization is not the most probable cause of the progressive increase in modulus because of the lower temperature and shorter duration of the thermal cycling steps.

\section{Conclusions}

We have observed a synergistic effect of two distinct networks, a DA type CAN and a MFC network, on the thermomechanical properties of the resulting composite material. The macromolecular DA type CAN was synthesized by furan functionalization of the copolymer $\mathrm{p}(\mathrm{E}$-alt-MA) and subsequent curing with a bismaleimide crosslinker. The design of the DA network allows dissolution in 

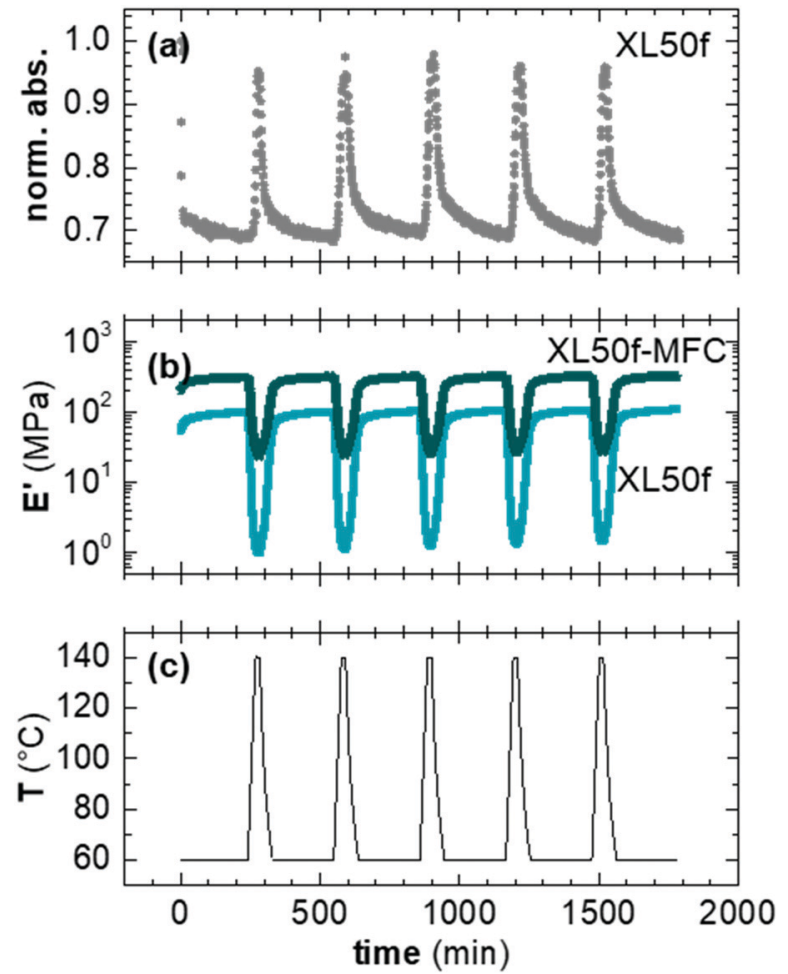

Fig. 6 Repeated thermal cycling of XL50f with and without MFC, (a) normalized IR absorbance of the maleimide peak of XL50f, (b) $E^{\prime}$ of XL50f with and without MFC obtained from DMA, and (c) temperature program during cycling.

DMF, a solvent in which MFC can be dispersed, enabling the formation of a second network based on physical interactions between cellulose fibrils. The combined effect of the networks is an increase in storage modulus by a factor of 60 at $80{ }^{\circ} \mathrm{C}$ and a decrease in creep strain by a factor of 40 at the same temperature. Further, the MFC network adds mechanical stability to the composite at elevated temperatures, where the DA network dissociates. The presence of a nanocellulose network hence prevents macroscopic flow while, according to the kinetic evaluation, it does not significantly affect the rate of the DA reaction.

Finally, the DA type network reinforced with MFC maintains its properties during at least 5 temperature cycles during which the reinforced CAN undergoes repeated association/dissociation.

\section{Conflicts of interest}

There are no conflicts to declare.

\section{Acknowledgements}

We gratefully acknowledge financial support from the Swedish Research Council Formas (grant no. 2018-00886) and the Swedish Foundation for Strategic Research (grant no. GMT14-0036). We thank Anders Mårtensson for help with elemental analysis. We thank Dr Anna I. Hofmann and Dr
Mariza Mone for expert help with photography and figure design, respectively.

\section{References}

1 W. Alabiso and S. Schlögl, The impact of vitrimers on the industry of the future: Chemistry, properties and sustainable forward-looking applications, Polymers, 2020, 12, 1660.

2 W. Denissen, J. M. Winne and F. E. Du Prez, Vitrimers: Permanent organic networks with glass-like fluidity, Chem. Sci., 2016, 7, 30-38.

3 D. J. Fortman, J. P. Brutman, G. X. De Hoe, R. L. Snyder, W. R. Dichtel and M. A. Hillmyer, Approaches to sustainable and continually recyclable cross-linked polymers, ACS Sustainable Chem. Eng., 2018, 6, 11145-11159.

4 C. J. Kloxin and C. N. Bowman, Covalent adaptable networks: Smart, reconfigurable and responsive network systems, Chem. Soc. Rev., 2013, 42, 7161-7173.

5 K. L. Jin, S. S. Kim, J. Xu, F. S. Bates and C. J. Ellison, Melt-blown cross-linked fibers from thermally reversible Diels-Alder polymer networks, ACS Macro Lett., 2018, 7, 1339-1345.

6 B. R. Elling and W. R. Dichtel, Reprocessable cross-linked polymer networks: are associative exchange mechanisms desirable?, ACS Cent. Sci., 2020, 6, 1488-1496.

7 A. Gandini, The furan/maleimide Diels-Alder reaction: A versatile click-unclick tool in macromolecular synthesis, Prog. Polym. Sci., 2013, 38, 1-29.

8 X. X. Chen, M. A. Dam, K. Ono, A. Mal, H. B. Shen, S. R. Nutt, K. Sheran and F. Wudl, A thermally remendable cross-linked polymeric material, Science, 2002, 295, 1698-1702.

9 A. Cuvellier, R. Verhelle, J. Brancart, B. Vanderborght, G. Van Assche and H. Rahier, The influence of stereochemistry on the reactivity of the Diels-Alder cycloaddition and the implications for reversible network polymerization, Polym. Chem., 2019, 10, 473-485.

10 B. J. Adzima, H. A. Aguirre, C. J. Kloxin, T. F. Scott and C. N. Bowman, Rheological and chemical analysis of reverse gelation in a covalently cross-linked Diels-Alder polymer network, Macromolecules, 2008, 41, 9112-9117.

11 Y. L. Liu and T. W. Chuo, Self-healing polymers based on thermally reversible Diels-Alder chemistry, Polym. Chem., 2013, 4, 2194-2205.

12 J. R. Davidson, G. A. Appuhamillage, C. M. Thompson, W. Voit and R. A. Smaldone, Design paradigm utilizing reversible Diels-Alder reactions to enhance the mechanical properties of 3D printed materials, ACS Appl. Mater. Interfaces, 2016, 8, 16961-16966.

13 L. Rulisek, P. Sebek, Z. Havlas, R. Hrabal, P. Capek and A. Svatos, An experimental and theoretical study of stereoselectivity of furan-maleic anhydride and furan-maleimide Diels-Alder reactions, J. Org. Chem., 2005, 70, 6295-6302.

14 Y. L. Fang, X. S. Du, Y. X. Jiang, Z. L. Du, P. T. Pan, X. Cheng and H. B. Wang, Thermal-driven self-healing and recyclable 
waterborne polyurethane films based on reversible covalent interaction, ACS Sustainable Chem. Eng., 2018, 6, 14490-14500.

15 C. Goussé, A. Gandini and P. Hodge, Application of the Diels-Alder reaction to polymers bearing furan moieties. 2 . Diels-Alder and retro-Diels-Alder reactions involving furan rings in some styrene copolymers, Macromolecules, 1998, 31, 314-321.

16 R. Gheneim, C. Perez-Berumen and A. Gandini, Diels-Alder reactions with novel polymeric dienes and dienophiles: Synthesis of reversibly cross-linked elastomers, Macromolecules, 2002, 35, 7246-7253.

17 P. Berto, A. Pointet, C. Le Coz, S. Grelier and F. Peruch, Recyclable telechelic cross-linked polybutadiene based on reversible Diels-Alder chemistry, Macromolecules, 2018, 51, 651-659.

18 L. M. Polgar, A. Kingma, M. Roelfs, M. van Essen, M. van Duin and F. Picchioni, Kinetics of cross-linking and de-cross-linking of EPM rubber with thermoreversible Diels-Alder chemistry, Eur. Polym. J., 2017, 90, 150-161.

19 S. A. Canary and M. P. Stevens, Thermally reversible crosslinking of polystyrene via the furan-maleimide Diels-Alder reaction, J. Polym. Sci., Part A: Polym. Chem., 1992, 30, 1755-1760.

20 J. M. Raquez, S. Vanderstappen, F. Meyer, P. Verge, M. Alexandre, J. M. Thomassin, C. Jerome and P. Dubois, Design of cross-linked semicrystalline poly( $\varepsilon$-caprolactone)based networks with one-way and two-way shape-memory properties through Diels-Alder reactions, Chem. - Eur. J., 2011, 17, 10135-10143.

21 K. Inoue, M. Yamashiro and M. Iji, Recyclable shapememory polymer: Poly(lactic acid) crosslinked by a thermoreversible Diels-Alder reaction, J. Appl. Polym. Sci., 2009, 112, 876-885.

22 L. Hammer, N. J. Van Zee and R. Nicolay, Dually crosslinked polymer networks incorporating dynamic covalent bonds, Polymers, 2021, 13, 396.

23 J. J. Cash, T. Kubo, D. J. Dobbins and B. S. Sumerlin, Maximizing the symbiosis of static and dynamic bonds in self-healing boronic ester networks, Polym. Chem., 2018, 9, 2011-2020.

24 L. Q. Li, X. Chen, K. L. Jin and J. M. Torkelson, Vitrimers designed both to strongly suppress creep and to recover original cross-link density after reprocessing: Quantitative theory and experiments, Macromolecules, 2018, 51, 5537-5546.

25 S. Wang, S. Q. Ma, O. Li, X. W. Xu, B. B. Wang, K. F. Huang, Y. L. Liu and J. Zhu, Facile preparation of polyimine vitrimers with enhanced creep resistance and thermal and mechanical properties via metal coordination, Macromolecules, 2020, 53, 2919-2931.

26 Y. J. Liu, Z. H. Tang, D. Wang, S. W. Wu and B. C. Guo, Biomimetic design of elastomeric vitrimers with unparalleled mechanical properties, improved creep resistance and retained malleability by metal-ligand coordination, J. Mater. Chem. A, 2019, 7, 26867-26876.
27 S. J. Eichhorn, A. Dufresne, M. Aranguren, N. E. Marcovich, J. R. Capadona, S. J. Rowan, C. Weder, W. Thielemans, M. Roman, S. Renneckar, W. Gindl, S. Veigel, J. Keckes, H. Yano, K. Abe, M. Nogi, A. N. Nakagaito, A. Mangalam, J. Simonsen, A. S. Benight, A. Bismarck, L. A. Berglund and T. Peijs, Review: Current international research into cellulose nanofibres and nanocomposites, J. Mater. Sci., 2010, 45, $1-33$.

28 A. Peterson, I. Östergren, A. Lotsari, A. Venkatesh, J. Thunberg, A. Ström, R. Rojas, M. Andersson, L. A. Berglund, A. Boldizar and C. Müller, Dynamic nanocellulose networks for thermoset-like yet recyclable plastics with a high melt stiffness and creep resistance, Biomacromolecules, 2019, 20, 3924-3932.

29 W. Zhao, Z. H. Feng, Z. H. Liang, Y. F. Lv, F. K. Xiang, C. Y. Xiong, C. Duan, L. Dai and Y. H. Ni, Vitrimer-cellulose paper composites: A new class of strong, smart, green, and sustainable materials, ACS Appl. Mater. Interfaces, 2019, 11, 36090-36099.

30 F. Lossada, J. Q. Guo, D. J. Jiao, S. Groeer, E. Bourgeat-Lami, D. Montarnal and A. Walther, Vitrimer chemistry meets cellulose nanofibrils: Bioinspired nanopapers with high water resistance and strong adhesion, Biomacromolecules, 2019, 20, 1045-1055.

31 S. Sain, D. Åkesson, M. Skrifvars and S. Roy, Hydrophobic shape-memory biocomposites from tung-oil-based bioresin and onion-skin-derived nanocellulose networks, Polymers, 2020, 12, 2470.

32 D. A. Kissounko, P. Taynton and C. Kaffer, New material: Vitrimers promise to impact composites, Reinf. Plast., 2018, 62, 162-166.

33 C. H. Xu, Z. J. Zheng, W. C. Wu, L. H. Fu and B. F. Lin, Design of healable epoxy composite based on beta-hydroxyl esters crosslinked networks by using carboxylated cellulose nanocrystals as crosslinker, Compos. Sci. Technol., 2019, 181, 107677.

34 E. Trovatti, A. G. Cunha, A. J. F. Carvalho and A. Gandini, Furan-modified natural rubber: A substrate for its reversible crosslinking and for clicking it onto nanocellulose, Int. J. Biol. Macromol., 2017, 95, 762-768.

35 E. Cudjoe, K. M. Herbert and S. J. Rowan, Strong, rebondable, dynamic cross-linked cellulose nanocrystal polymer nanocomposite adhesives, ACS Appl. Mater. Interfaces, 2018, 10, 30723-30731.

36 J. L. Swartz, R. L. Li and W. R. Dichtel, Incorporating functionalized cellulose to increase the toughness of covalent adaptable networks, ACS Appl. Mater. Interfaces, 2020, 12, 44110-44116.

37 Y. Ouyang, M. Mauri, A. M. Pourrahimi, I. Östergren, A. Lund, T. Gkourmpis, O. Prieto, X. Xu, P.-O. Hagstrand and C. Müller, Recyclable polyethylene insulation via reactive compounding with a maleic anhydride-grafted polypropylene, ACS Appl. Polym. Mater, 2020, 2, 2389-2396.

38 R. Araya-Hermosilla, G. M. R. Lima, P. Raffa, G. Fortunato, A. Pucci, M. E. Flores, I. Moreno-Villoslada, A. A. Broekhuis and F. Picchioni, Intrinsic self-healing thermoset through 
covalent and hydrogen bonding interactions, Eur. Polym. J., 2016, 81, 186-197.

39 A. Gandini, D. Coelho and A. J. D. Silvestre, Reversible click chemistry at the service of macromolecular materials. Part 1: Kinetics of the Diels-Alder reaction applied to furanmaleimide model compounds and linear polymerizations, Eur. Polym. J., 2008, 44, 4029-4036.

40 Y. Zhu, J. Hu, H. Luo, R. J. Young, L. Deng, S. Zhang, Y. Fan and G. Ye, Rapidly switchable water-sensitive shapememory cellulose/elastomer nano-composites, Soft Matter, 2012, 8, 2509-2517.

41 J. Sapkota, S. Kumar, C. Weder and J. E. Foster, Influence of processing conditions on properties of poly(vinyl acetate)/ cellulose nanocrystal nanocomposites, Macromol. Mater. Eng., 2015, 300, 562-571.

42 J. Aizpurua, L. Martin, E. Formoso, A. Gonzalez and L. Irusta, One pot stimuli-responsive linear waterborne polyurethanes via Diels-Alder reaction, Prog. Org. Coat., 2019, 130, 31-43.

43 E. Dolci, G. Michaud, F. Simon, B. Boutevin, S. Fouquay and S. Caillol, Remendable thermosetting polymers for isocyanate-free adhesives: A preliminary study, Polym. Chem., 2015, 6, 7851-7861.

44 J. Aizpurua, L. Martin, M. Fernández, A. González and L. Irusta, Recyclable, remendable and healing polyurethane/acrylic coatings from UV curable waterborne dispersions containing Diels-Alder moieties, Prog. Org. Coat., 2020, 139.

45 X. Z. Xu, F. Liu, L. Jiang, J. Y. Zhu, D. Haagenson and D. P. Wiesenborn, Cellulose nanocrystals vs. cellulose nanofibrils: A comparative study on their microstructures and effects as polymer reinforcing agents, ACS Appl. Mater. Interfaces, 2013, 5, 2999-3009.

46 X. X. Liu, P. F. Du, L. Liu, Z. Zheng, X. L. Wang, T. Joncheray and Y. F. Zhang, Kinetic study of Diels-Alder reaction involving in maleimide-furan compounds and linear polyurethane, Polym. Bull., 2013, 70, 2319-2335.

47 E. Goiti, F. Heatley, M. B. Huglin and J. M. Rego, Kinetic aspects of the Diels-Alder reaction between poly(styrene-cofurfuryl methacrylate) and bismaleimide, Eur. Polym. J., 2004, 40, 1451-1460.
48 Y. L. Liu, C. Y. Hsieh and Y. W. Chen, Thermally reversible cross-linked polyamides and thermo-responsive gels by means of Diels-Alder reaction, Polymer, 2006, 47, 2581-2586.

49 Y. L. Liu and C. Y. Hsieh, Crosslinked epoxy materials exhibiting thermal remendablility and removability from multifunctional maleimide and furan compounds, J. Polym. Sci., Part A: Polym. Chem., 2006, 44, 905-913.

50 A. Smedberg, T. Hjertberg and B. Gustafsson, The role of entanglements in network formation in unsaturated low density polyethylene, Polymer, 2004, 45, 4867-4875.

51 J. P. Flory, Networks, in Encyclopedia of polymer science and engineering, ed. H. F. B. N. M. Mark, C. G. Overberger and G. Menges, Wiley, New York, 1987, vol. 10, pp. 95-112.

52 M. Mauri, A. Peterson, A. Senol, K. Elamin, A. Gitsas, T. Hjertberg, A. Matic, T. Gkourmpis, O. Prieto and C. Müller, Byproduct-free curing of a highly insulating polyethylene copolymer blend: An alternative to peroxide crosslinking, J. Mater. Chem. C, 2018, 6, 11292-11302.

53 D. Klemm, F. Kramer, S. Moritz, T. Lindström, M. Ankerfors, D. Gray and A. Dorris, Nanocelluloses: A new family of nature-based materials, Angew. Chem., Int. Ed., 2011, 50, 5438-5466.

54 V. Favier, G. R. Canova, J. Y. Cavaille, H. Chanzy, A. Dufresne and C. Gauthier, Nanocomposite materials from latex and cellulose whiskers, Polym. Adv. Technol., 1995, 6, 351-355.

55 P. K. Annamalai, K. L. Dagnon, S. Monemian, E. J. Foster, S. J. Rowan and C. Weder, Water-responsive mechanically adaptive nanocomposites based on styrene-butadiene rubber and cellulose nanocrystals: Processing matters, ACS Appl. Mater. Interfaces, 2014, 6, 967-976.

56 J. R. Capadona, K. Shanmuganathan, D. J. Tyler, S. J. Rowan and C. Weder, Stimuli-responsive polymer nanocomposites inspired by the sea cucumber dermis, Science, 2008, 319, 1370-1374.

57 C. D. Diakoumakos and J. A. Mikroyannidis, Polyimides derived from Diels-Alder polymerization of furfurylsubstituted maleamic acids or from the reaction of bismaleamic with bisfurfurylpyromellitamic acids, J. Polym. Sci., Part A: Polym. Chem., 1992, 30, 2559-2567. 